\title{
SUSTAINED MACROSCOPIC DEFLECTED FATIGUE CRACK GROWTH IN NICKEL BASED SUPERALLOY 720LI
}

\author{
C. Schoettle ${ }^{1}$, P.A.S. Reed ${ }^{1}$, M.J. Starink ${ }^{1}$, I. Sinclair ${ }^{1}$, D.J. Child ${ }^{2}$, G.D. West ${ }^{2}$, R.C. Thomson ${ }^{2}$ \\ ${ }^{1}$ Engineering Materials Group, University of Southampton, Highfield, Southampton, SO17 1BJ, UK \\ ${ }^{2}$ Department of Materials, Loughborough University, Loughborough, LE11 3TU, UK
}

Keywords: Alloy 720Li, fatigue, micromechanisms of crack growth, deflected crack growth

\begin{abstract}
Sustained deflected crack growth is a concern as we need to understand both the factors which cause it and when it may happen in a component to ensure we have appropriate lifing strategies in place. This behaviour has been reported in a number of fine-grained $\mathrm{Ni}$-based turbine disc alloys at intermediate temperatures $\left(200-600^{\circ} \mathrm{C}\right)$. Such fracture surfaces show a competition between opening and shear modes of crack growth, with macroscopic deflection being initiated from the free surface. The interaction of the crack and surrounding microstructure have been studied via serial sectioning using a focused ion beam, allowing a reconstruction based on combined 3D electron back scatter diffraction (EBSD) and energy dispersive spectroscopy (EDS) to be produced. This showed both intergranular and transgranular crack growth modes occurring in the deflected crack growth and no obvious influence of grain orientation or texture to explain the crack deflection. Visualisation and representation of such data-rich images is challenging - the additional compositional (phase identification), orientation and deformation/strain mapping features of this approach together with the spatial information in 3D may require new approaches to data presentation.
\end{abstract}

\section{Introduction}

Nickel based superalloys are used for high temperature applications, such as aeroengine components, due to their high temperature strength and oxidation resistance. For safety critical components (such as a turbine disc) it is necessary to declare lives to ensure that risk of failure is extremely remote. As such, it is important that crack growth behaviour is predictable so that catastrophic failure can be avoided. Under mode I (tensile) loading, a crack is usually expected to grow in a plane perpendicular to the stress axis; however a sustained macroscopic deflected fatigue crack growth, previously also referred to as 'teardrop cracking' (TDC), has been observed in the superalloy, Alloy 720Li [1]. This phenomenon exhibits considerable deflection from the expected crack growth plane. In previous work $[1,2,3]$, tests have been carried out on rectangular specimens with a corner notch $(\mathrm{CN})$ and large shear regions are observed, typically at $30-45^{\circ}$ to the loading direction, extending in from the specimen free surface and enclosing a central planar 'teardrop' shaped region perpendicular to the loading direction.

The same phenomenon, showing shear regions initiated from the free surfaces, has also been reported [1] in Single Edge Notched samples in bend (SENB). Previous work carried out by Brooks and Rainforth [3] and Loo-Morrey and Reed [2] showed that TDC was particularly observed at temperatures between $200^{\circ} \mathrm{C}$ and $500^{\circ} \mathrm{C}$ in air. At temperatures above $500^{\circ} \mathrm{C}$ in air, the expected planar crack shape was present again, however tests performed in vacuum showed tear drop cracking was retained to higher temperatures of $600^{\circ} \mathrm{C}$. The effect has been linked to the prevalence of planar slip which can be seen in these alloys, which is linked to the shearing of the ordered $\gamma^{\prime}$ precipitates.

At higher temperatures (above $760^{\circ} \mathrm{C}$ ) slip behaviour gets more homogenous, as cross slip occurs [4] although vacuum conditions also promote heterogenous (planar) slip, as slip tends to be more reversible in the absence of oxidation. [1]. A clear link between slip heterogeneity and this deflected crack growth cannot be made as sustained deflected crack growth cannot be seen at room temperature where planar slip is expected.

An apparently similar deflection behaviour has been observed in U720 by Tong [5] in quasi static tests, with very low frequency and long dwells at $650^{\circ} \mathrm{C}$ in compact tension (CT) specimens, where deflected and planar cracking occurred. Stress intensity factors have been evaluated using finite element (FE) software ANSYS, where $K_{I}$ and $K_{\text {II }}$ were calculated from the crack tip opening displacement. This showed an increase in the $\mathrm{K}_{\mathrm{II}} / \mathrm{K}_{\mathrm{I}}$ ratio for the growing crack. No obvious explanation has been found to rationalise the observed deflections, however Tong made links to work by Cotterell [6], which proposes that mixed mode fracture can be caused by crack path instability. For a crack that deflects on a microscopic scale due to local inhomogeneity, the local mode I and mode II condition may then influence whether it is unstable and deflects further or is stable and returns to the original crack path.

The actual occurrence of the unstable crack growth may also depend on other factors such as the crack growth mechanism or grain size. Pook [7] summarised some work on deflected crack paths, where he describes crack deflection in a similar way. The crack path is described as chaotic, with initial deviations from the planar crack path occurring due to microstructural variation, which can cause the crack to either follow a stable or unstable crack path.

Sustained deflected crack growth in fatigue has been reported in other alloy systems: Strongly deflected crack growth has also been reported in Udimet 720 single crystal systems in mixed mode loading and under vacuum conditions, where fatigue behaviour is even more controlled by planar slip processes [8]. The direction of the Stage I deflected crack growth was found to be dependent on the crystallographic primary and secondary orientations as well as loading conditions. Consideration of the local resolved shear-stress intensity and local resolved normalstress intensity for each slip system as it intersected the nominal crack-growth plane allowed the prediction of stage I crack paths. A combination of both opening and shearing was found to promote stage I crack growth, and boundary conditions were established within which stage I cracking was promoted. Highly deflected stage I cracking gave rise to significant shielding effects, but under suitable mixed-mode loading, highly oriented, coplanar 
stage I crack growth was produced. Intrinsic stage I cracking under mixed-mode loading appeared to be greatly accelerated compared with mode I-dominated stage II crack growth for comparable stress-intensity levels [8].

Deflected crack growth behaviour has also been observed in aluminium alloys tested under mixed mode loading in fatigue, where crack propagation occurs along grain boundaries [9]. The deflection from the expected nominal crack plane has been linked to either strongly textured alloys with high volume fractions of shearable $\delta^{\prime}\left(\mathrm{Al}_{3} \mathrm{Li}\right)$ precipitates where slip band crack growth has been promoted or specific alignments where grain boundary failure processes (principally shear controlled) have dominated fatigue failure. For the alloy AA7050, for a number of mixity conditions and initial $K_{e q \text { max }}$ values the fracture deflection angles were measured and compared to predictions using conventional mixed mode analyses such as maximum tangential stress (MTS), $G_{\max }$ and $S_{\min }$. The first approach states that crack behaviour is controlled by some component of the crack tip stress or strain field - Maximum Tangential Stress (MTS). The second extends Griffith's elastic energy release rate concept to mixed mode loading conditions - fracture is controlled by $G_{\max }$. The third suggests that a "strain energy density" may be evaluated in the vicinity of the crack tip and that this quantity controls crack behaviour, with the crack following the direction of minimum strain energy density $S_{\min }$ [10]. It was found that the deflection angle decreased from the predicted angle (assuming MTS, $G_{\max }$ or $S_{\text {min }}$ controls crack growth) at a $K_{\text {eff.max }}$ above $10 \mathrm{MPa} \sqrt{\mathrm{m}}$ and that for increased $K_{I I} / K_{I}$ mixed mode grain boundary failure seems to be sustained. [9]

Previous studies [1] have proposed a definition of the onset of sustained shear crack growth in the current material (related to crack deflection beyond the expected plane stress plastic zone) and applied this to different test geometries in different temperatures and environments. The onset of such sustained deflected crack growth has been found to occur between $\Delta \mathrm{K}$ levels of 23-27 MPa $\sqrt{ } \mathrm{m}$ [1]. Scanning electron microscope (SEM) analyses of the fracture surfaces have shown a competition between the sustained shear and mode I crack growth modes in both the terraced shear lip and flat tear drop region, which indicates that the macroscopic deflection is triggered by the free surface. The tilt angles measured from the deflections have been used to assess the mixed mode stress state giving rise to deflected shear growth.

No clear mechanism causing this deflection has yet been identified. It is therefore necessary to both develop an understanding of the mechanism and develop assessment methodologies for component lifing. If a crack grows in an "unexpected" deflected direction it may experience very different loading from that assumed for a planar crack growing under mode I loading, with concomitant potentially detrimental effects on inspection intervals and expected life. This work aims to establish whether the crack path reported previously is linked directly to any microstructural features, to further assess the operative micromechanisms.

\section{Materials}

In this work, the crack growth behavior of a cast and wrought, fine grained superalloy $720 \mathrm{Li}$ alloy has been studied. The composition of the alloy is given in Table I.

Table I: Composition of Alloy $720 \mathrm{Li}, \mathrm{Fe}$ is a trace element

\begin{tabular}{|l|l|l|l|l|l|}
\hline Element & $\mathrm{Wt} \%$ & Element & $\mathrm{Wt} \%$ & Element & $\mathrm{Wt} \%$ \\
\hline $\mathrm{Cr}$ & 17.7 & $\mathrm{Al}$ & 2.6 & $\mathrm{~B}$ & 0.016 \\
$\mathrm{Co}$ & 14.5 & $\mathrm{~W}$ & 1.2 & $\mathrm{C}$ & 0.014 \\
$\mathrm{Ti}$ & 5.0 & $\mathrm{Fe}$ & 0.2 & $\mathrm{Ni}$ & Bal. \\
$\mathrm{Mo}$ & 3.0 & $\mathrm{Zr}$ & 0.037 & & \\
\hline
\end{tabular}

The heat treatment [11] consisted of a $4 \mathrm{~h}$ solution heat treatment between $1080-1100^{\circ} \mathrm{C}$ followed by an oil quench and then a single age heat treatment of $16 \mathrm{~h}$ at $760^{\circ} \mathrm{C}$ followed by an air cool.

The microstructure was assessed to characterise grain size and $\gamma^{\prime}$ distributions in the material. The mounted samples were ground with 600 and 1200 grit $\mathrm{SiC}$ paper and then polished with a $9 \mu \mathrm{m}$ diamond suspension, followed by a $3 \mu \mathrm{m}$ diamond suspension and finally a $0.25 \mu \mathrm{m}$ colloidal silica polish. Etching was carried out on the polished samples with Nimonic Etch $\left(40 \mathrm{ml} \mathrm{H}_{2} \mathrm{O}, 10 \mathrm{ml}\right.$ $\mathrm{HNO}_{3}, 50 \mathrm{ml} \mathrm{HCl}, 2.5 \mathrm{~g} \mathrm{CuCl}_{2}$ ). Typical etching times were 10 to 15 seconds. To overcome the poor contrast, a binary image of the grain structure and the primary $\gamma^{\prime}$ was produced manually by carefully tracing over enlarged SEM micrographs. To produce the $\gamma$ grain size information, the primary $\gamma^{\prime}$ were omitted and grain boundaries interpolated in those regions. For secondary $\gamma^{\prime}$, the precipitates were outlined from SEM micrographs of the microstructure where the $\gamma^{\prime}$ had been etched out. The binary images were then scanned and archived for further analysis. To measure grain and precipitate size and distribution, an automatic image analysis software, ImageJ, was used. The pictures were scaled and parameters such as perimeter, area and Feret diameters of the grain and primary and secondary $\gamma^{\prime}$ binary images were measured. Incomplete objects at the edge of the binary image were removed using the image analysis software. The number of objects analysed for grain size, primary $\gamma^{\prime}$ and secondary $\gamma^{\prime}$ particle size were at least 100, 500 and 200 respectively.

Electron back scatter diffraction (EBSD) scans were also carried out on plain polished samples. EBSD data were collected using a Hikari EBSD camera, attached to an FEI Nova 600 Nanolab DualBeam FEG SEM/FIB system. Data collection at a rate of 30 points per second was performed over a scan area of approximately 200 $\mu \mathrm{m} \times 200 \mu \mathrm{m}$. Both $\gamma$ and $\gamma^{\prime}$ phases were indexed to a nickel structure file with a lattice parameter of $3.52 \AA$.

Figure 1 shows the variability in grain size in the cast and wrought $(\mathrm{C} \& \mathrm{~W})$ material, which is linked to the processing route. There is clear evidence of grain size banding in the structure (with coarser grain sizes evident in the centre of the image) $[12,13]$. The primary $\gamma^{\prime}$ positions can be inferred from this picture and some primary $\gamma^{\prime}$ appear to sit within grains as well as at the expected position of the grain boundaries. Twins can be clearly seen in this figure and in Figure 2 a. An estimation of secondary $\gamma^{\prime}$ sizes and distributions can be made from Figure $2 \mathrm{~b}$. Grain and precipitate measurements from these graphs are summarised in Table II. 


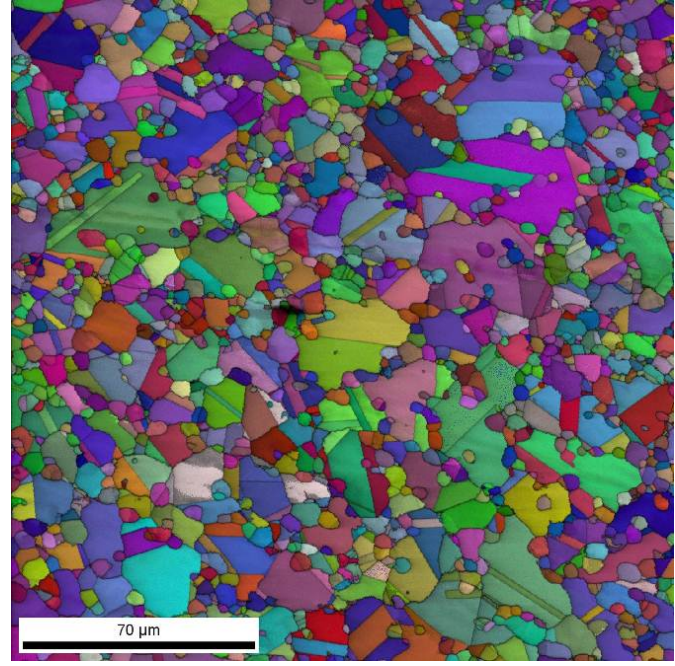

Figure 1: Microstructure of Alloy 720Li C\&W: EBSD image from plain polished sample showing variation in grain size (banding of finer and coarser grains) and location of primary $\gamma^{\prime}$ (sometimes within grains as well as at grain boundaries)

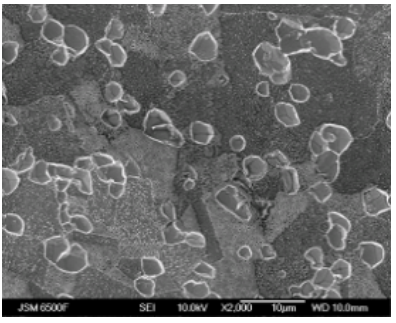

(a)

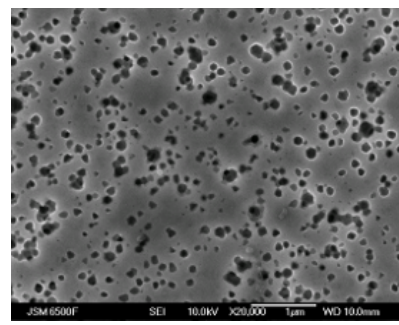

(b)
Figure 2: Secondary electron micrographs of sample after Nimonic etch (applied for $10 \mathrm{sec}$ ) (a) showing grain structure and etched out primary $\gamma^{\prime}$, (b) close-up of secondary $\gamma^{\prime}$ [1]

Table II: Grain size and $\gamma^{\prime}$ size of the materials [1]

\begin{tabular}{|l|l|l|l|l|}
\hline $\begin{array}{l}\text { Grain } \\
\text { Size }\end{array}$ & $\begin{array}{l}\text { Primary } \\
\gamma^{\prime} \text { size }\end{array}$ & $\begin{array}{l}\text { Primary } \gamma^{\prime} \\
\text { volume } \\
\text { fraction }\end{array}$ & $\begin{array}{l}\text { Secondary } \\
\gamma^{\prime} \text { size }\end{array}$ & $\begin{array}{l}\text { Secondary } \gamma^{\prime} \\
\text { volume } \\
\text { fraction }\end{array}$ \\
\hline $\begin{array}{l}16.7 \mu \mathrm{m} \\
(\text { Range }\end{array}$ & $\begin{array}{l}5.1 \mu \mathrm{m} \\
(\text { Range }\end{array}$ & $17.1 \%$ & $\begin{array}{l}146 \mathrm{~nm} \\
\text { (Range }\end{array}$ & $15.8 \%$ \\
$\begin{array}{l}4.5-45.3 \\
\mu \mathrm{m})\end{array}$ & $\begin{array}{l}1.6-23.5 \\
\mu \mathrm{m})\end{array}$ & & $\begin{array}{l}45-625 \\
\mathrm{~nm})\end{array}$ & \\
\hline
\end{tabular}

\section{Experimental methodology}

A fatigue test has been carried out at $300^{\circ} \mathrm{C}$ in air in an Instron servohydraulic testing machine fitted with a high temperature vacuum chamber. The stress intensity factor $K$ in the corner notched bend specimen (see Figure 3) was calculated after
Pickard [14]. Crack growth was initiated at a $\Delta K$ level of $\sim 12$ $\mathrm{MPa} \sqrt{\mathrm{m}}$ under a constant load range, thus allowing the crack to grow out under increasing $\Delta K$ conditions. The test is described in more detail in [1].

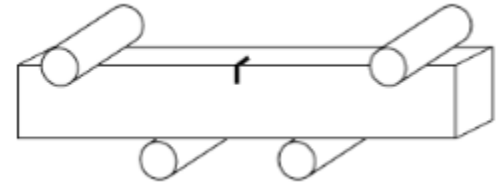

(a)

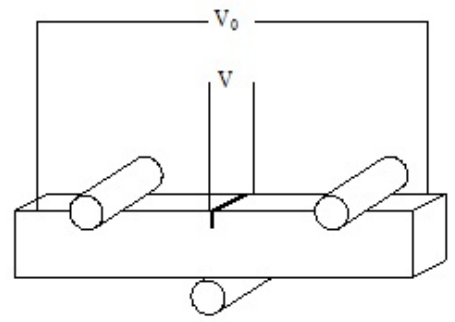

(b)

Figure 3: Test specimen geometries used, specimen dimensions: $12.5 \mathrm{~mm}$ by $12.5 \mathrm{~mm}$ by $80 \mathrm{~mm}$ (a) corner notch bend (CNB) sample in 4 point bend loading, loading span $=15 \mathrm{~mm}$, corner notch $=0.85 \mathrm{~mm}$ (b) single edge notched bend (SENB) sample in 4 point bend loading, notch depth $=3.125 \mathrm{~mm}$ [1]

SENB tests have also been carried out at $300^{\circ} \mathrm{C}$ and $600^{\circ} \mathrm{C}$ in air and vacuum and reported fully in [1]. Samples of the same bar dimensions as above, with an edge notch were precracked (at constant $\Delta K=20 \mathrm{MPa} \sqrt{\mathrm{m}}$ ) to provide a sharp starter crack and subsequent crack growth under constant load range (and thus increasing $\Delta K$ levels, starting from a value of $\Delta K=20 \mathrm{MPa} \sqrt{\mathrm{m}}$ ) was monitored using Potential Difference (P.D.) techniques. The current study focuses on subsequent more detailed failure investigations on selected test specimens from the previously reported work. The aim is to further elucidate the micromechanisms controlling the macroscopically deflected crack growth behavior.

The complex 3D crack shapes of the tear drop fracture surfaces have been mapped using the Alicona Infinite Focus profilometer, a system in which a microscope scans over the fracture surface and automatically focuses on each point and then determines the height profile. Vertical resolutions of up to $10 \mathrm{~nm}$ can be achieved; however for this work the resolution used was $5 \mu \mathrm{m}$ The deflection angles could be measured from these 3D maps. The fracture surfaces post-failure were observed under a Field Emission Gun Scanning Electron Microscope (FEG-SEM). Secondary electron images were produced on a JEOL JSM6500F FEG-SEM at an accelerating voltage of $10 \mathrm{kV}$. Fracture surfaces and polished profiles of the side of the fracture were also examined.

Once the surface of a fractured sample had been polished to reveal large secondary cracks, the tips of these have been analysed in more detail. Work at Loughborough University using focused ion 
beam (FIB) serial sectioning and EBSD data collection has enabled a 3D reconstruction of the crack-tip region. EBSD data were collected using a Hikari EBSD camera attached to an FEI Nova 600 Nanolab Dual-Beam FEG SEM/FIB system. Data collection at a rate of 30 points per second was performed over a scan area of approximately $40 \times 40 \times 30 \mu \mathrm{m}$. A relatively slow collection speed was used as EDS data were collected simultaneously, using an EDAX Silicon Drift Detector Apollo XL (SDD) at an input count rate of $325 \mathrm{k}$ counts per second and a processing time of $0.5 \mathrm{~ms}$, to the EBSD data to enable $\gamma$ and $\gamma^{\prime}$ to be differentiated by their compositional differences. The EBSD data were processed using TSL OIM Analysis 5.31 and reconstructed using Avizo 6.0.0 software as described in [15].

\section{Results}

The overall fracture surface of the CNB test at $300^{\circ} \mathrm{C}$ in air is shown in Figure 4. The test shows apparent terraced shear lips, which indicate alternating deflected and mode I controlled crack growth is occurring, which appears to be triggered from the free surface (plane stress region). It should however be noted that the plane stress region is expected to produce shear lips, it is important to establish to what extent the shear crack growth is sustained beyond the expected plane stress plastic zone size. The onset of sustained deflected crack growth has been proposed [1] to be deflection beyond the expected plane stress plastic zone size (PZS) and has been found to range between $25-27 \mathrm{MPa} \vee \mathrm{m}$ for both specimen geometries.

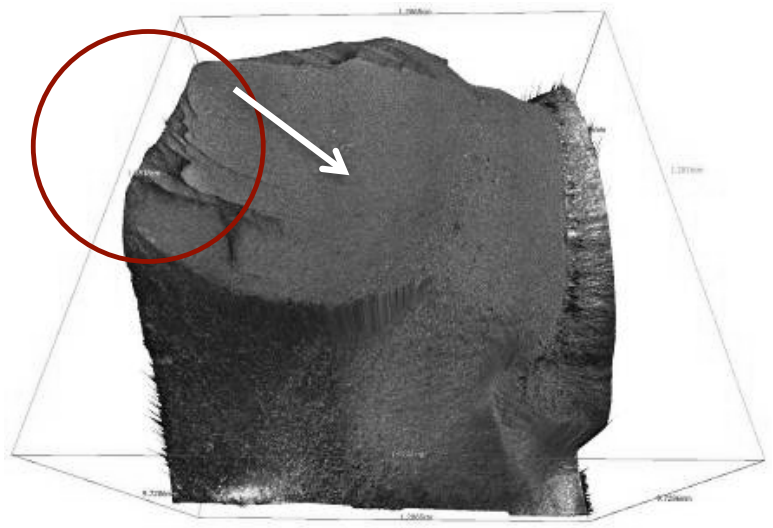

Figure 4: 3D profile created in Alicona Infinite Focus of CNB sample tested at $300^{\circ} \mathrm{C}$ in air. The circle indicates a terrace region (shear lip region) and the arrow shows the general crack growth

direction in the Stage II growth region. The starter notch is located at the rear left hand corner of the fracture surface.

Detailed examination of the CNB fracture surfaces at $300^{\circ} \mathrm{C}$ in air in the SEM showed the following features: In the terraced (deflected region) indicated by the circled area in Figure 4, higher magnification SEM images can be seen in Figure 5. Figure 5 (a) shows one of the flat (mode I controlled) terraces on the right hand side of the image and a deflected region on the left hand side of the image, clearly mode I and shear controlled regions alternate here. Figure 5(a) also shows secondary cracks which are converging the closer they are to the shear regions, with a very distinct secondary crack running along the transition between the shear and flat regions (seen at higher magnification in Fig 5b).

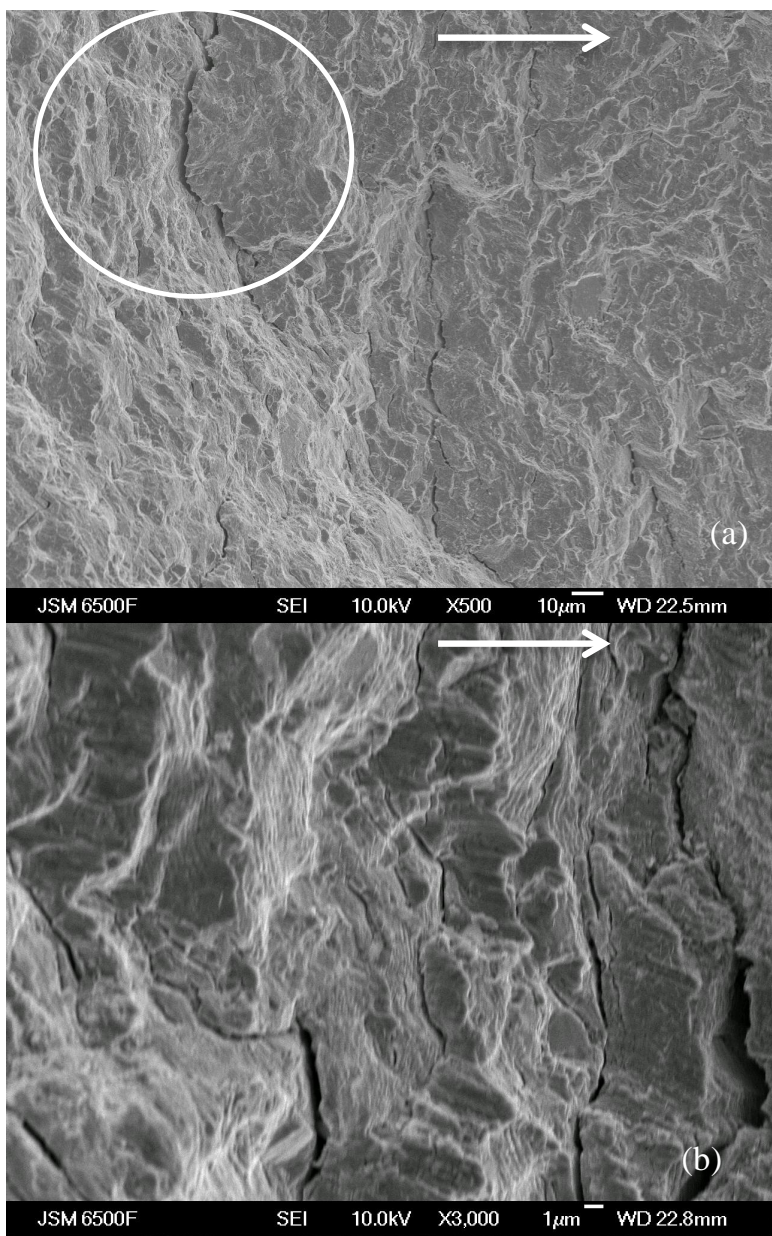

Figure 5: Fracture surface of U720Li $\mathrm{C} \& \mathrm{~W}$ at $300^{\circ} \mathrm{C}$ in air, focusing into the terraced (shear lip) region: Arrow indicates overall crack growth direction (a) $\Delta \mathrm{K} \approx 75 \mathrm{MPa} \sqrt{\mathrm{m}}$ showing deflected crack growth on the left and flat stage II growth on the right and a large secondary crack between the two growth modes (b) at higher magnification showing large secondary cracks. Although these images have been taken at very high $\Delta \mathrm{K}$ levels, this shear cracking mode is also observed at relatively low $\Delta \mathrm{K}$ levels [1].

Figure 6 (a) and (b) show the flat 'tear drop' region, indicated by the arrowed region in Figure 4, where predominantly flat, transgranular Stage II crack growth can be observed.

'Striation' like features and corresponding secondary cracks can also be observed that change their orientation with grain size periodicity, indicating that they are slip traces. The presence of these secondary cracks appears to indicate secondary (possibly deflected shear) crack growth occurs even while Stage II crack growth predominates in this region. A competition between the two processes seems to explain the switching on and off of the deflected crack growth mechanism seen in both regions. 


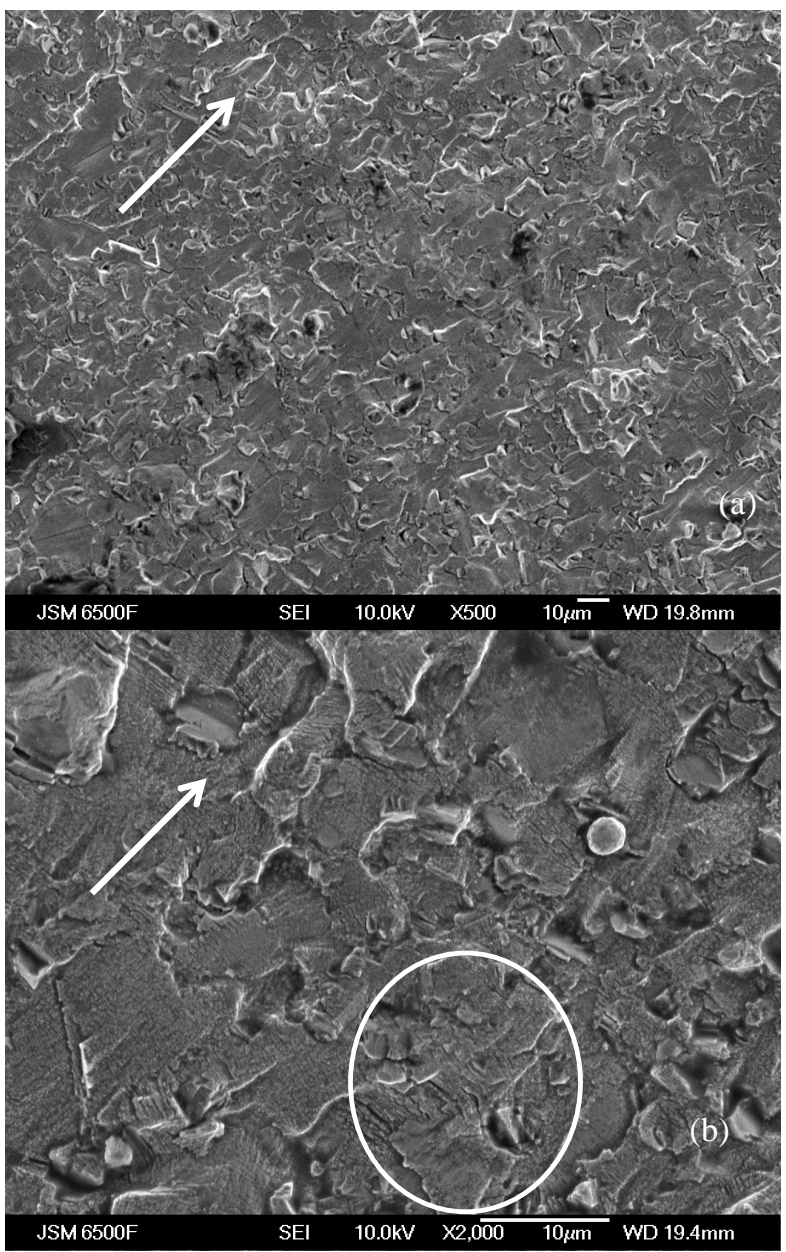

Figure 6 : Fracture surface of $\mathrm{U} 720 \mathrm{Li} \mathrm{C} \& \mathrm{~W}$ at $300^{\circ} \mathrm{C}$ in air, focusing into the Stage II (tear drop) region: Arrow indicates overall crack growth direction (a) at $\Delta \mathrm{K} \approx 42 \mathrm{MPa} \sqrt{\mathrm{m}}$ in Stage II portion of "tear-drop" region (Arrows again indicate crack growth direction). (b) at higher magnification. Circles indicate secondary cracks, indicating shear cracking is occurring within the main Stage II region as well. [1]

Similar behavior has been observed in the SENB samples [1] with a greater extent of deflected crack growth being observed at the specimen sides than might be predicted from simple plane stress effects. The side-surface of a fractured sample has been polished, as described in Experimental Methodology, to reveal more detail of these large secondary cracks. These have been observed in the SEM, as shown in Figure 6. The large secondary crack continuing from the shear terrace bifurcates and one crack tip continues in the shear direction, while the other continues approximately in the opening direction. Etching reveals the secondary crack can be observed to grow between some primary $\gamma^{\prime}$, but then continues to grow through a larger $\gamma$ grain. It bifurcates in this grain and then stops. This surface observation does not indicate that the crack path follows any specific microstructural features, and there is no clear evidence of a preference for either intergranular failure, $\gamma^{\prime}$ decohesion or transgranular or slip-band dominated crack growth. It would be useful to be able to assess more completely the crack tip growth mechanisms of such deflected cracks over a more representative area than revealed by a simple surface observation, and to this end the FIB serial sectioning and EBSD data collection have been used on one of these secondary crack tips (from a CNB sample) to build up a $3 \mathrm{D}$ reconstruction of the crack-tip region.

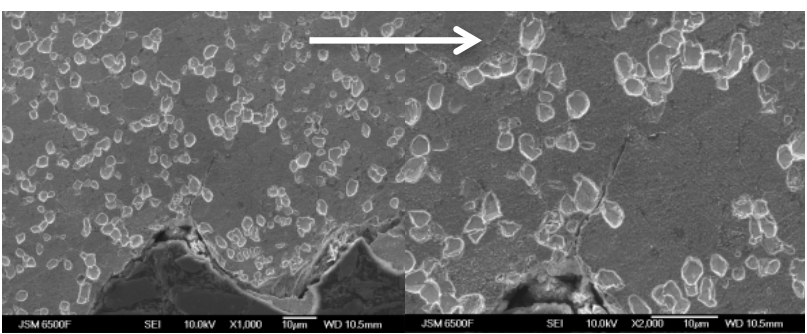

Figure 6: Secondary electron image showing a secondary crack in SENB U720Li C\&W at $300{ }^{\circ} \mathrm{C}$ in air (a) starting at $\Delta \mathrm{K}=29$ $\mathrm{MPa} \sqrt{\mathrm{m}}$ (b) at higher magnification. Microstructure revealed with

Nimonic etch. Arrow indicates general mode I controlled crack propagation direction

Figure 7 shows the secondary crack-tip region that has been examined further using the FIB and EDX serial sectioning and reconstruction approach. It can be seen that this is a fairly substantial secondary crack, which has arrested. The final major deflection can be seen to the left of the image. The chosen secondary crack started from a main crack length of $\sim 5.1 \mathrm{~mm}$, at which the nominal $\Delta \mathrm{K}$ level is $45.6 \mathrm{MPa} \sqrt{\mathrm{m}}$. The final assessed volume is small, $30 \times 40 \times 30 \mathrm{um}^{3}$.

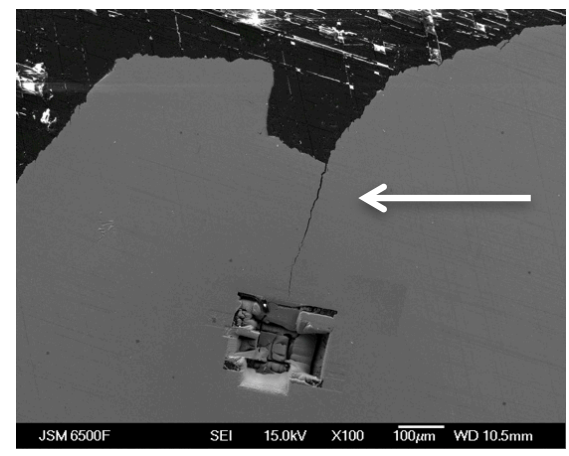

Figure 7: Secondary electron image showing an area on the CNB sample from which a 3D volume was extracted, showing the secondary crack. Arrow indicates general mode I controlled crack propagation direction.

A series of $2 \mathrm{D}$ slices were produced which can be viewed in a number of different modes: Image quality can be used as a proxy for the crack itself, i.e. very poor image quality regions, define the crack, so we can isolate it, allowing the crack plane to be segmented out (Figure 8), EBSD data can be gathered to identify the location (and orientation) of grains and precipitates. The grains and precipitates adjacent to the crack have been individually selected in each of the slices, using slices showing Image Quality (IQ) from the EBSD. The slices 
of the EBSD results have then been reconstructed, and the grains adjacent to the crack have been individually selected to show their interaction with the crack, as shown in Figure 9. The colours of the inverse pole figure (IPF) represent an average grain orientation in 2D space. Grain orientation (IPF) colours are added from the 2D EBSD slices manually, which therefore means small variations inside each grain are not considered. The crack has been reconstructed in the same manner from the IQ maps. The 3D reconstruction of the crack (Figure 8) shows areas where it seems to deflect around grains, and other quite planar areas indicating failure along slip bands. The crack tip (going into the page) appears discontinuous, further evaluation of the microstructure features ahead of the crack tip should help to identify which features arrest the crack or aid it's propagation. By its very nature though, this detailed sectioning, analysis and subsequent assessment is restricted to small volumes of material.

Figure 9 shows the crack tip and adjacent grains with the IPF colours representing grain orientation, indicated by the key. From the particular sample volume reconstructed the following observations can be made: It can be seen that the crack is sometimes growing along the grain boundaries (and possibly avoiding primary $\gamma^{\prime}$ ), but also through large grains, where it is showing quite planar (perhaps slip-band) crack growth. Twin boundaries do not seem to affect growth. These 3D data suggest that crack growth is more transgranular towards the crack tip. The crack tip itself is discontinuous and this technique shows how further detailed evaluation of the microstructure ahead of the crack tip can be obtained, giving greater insight into what promotes, arrests or deflects local crack growth. This detailed investigation has also shown that there is no simple or obvious relationship between this deflected crack growth and grain orientation thus confirming that this phenomenon is not affected by local texture effects.

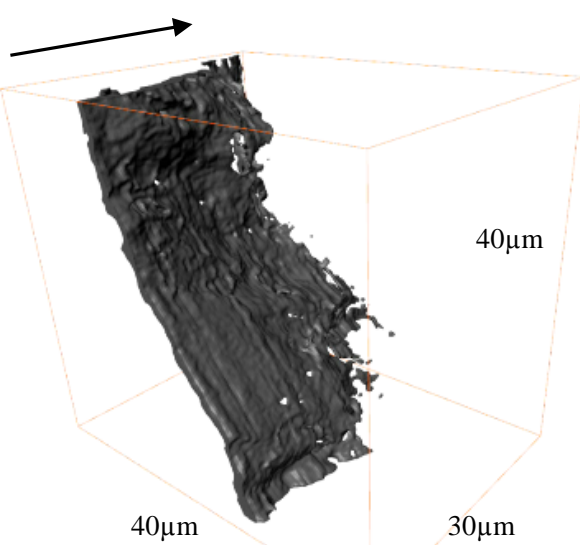

Figure 8: Reconstruction of the secondary crack (arrow indicates the secondary crack growth direction) Primary crack growth direction is out of the page

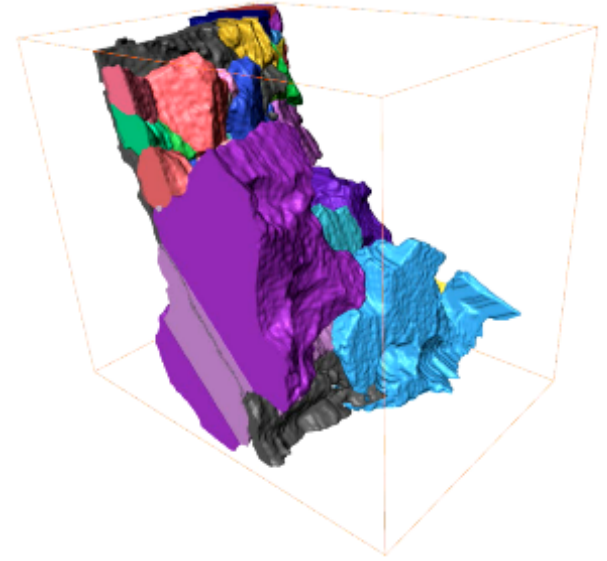

Figure 9: Crack and adjacent grains in IPF colours, showing intergranular and transgranular crack growth.
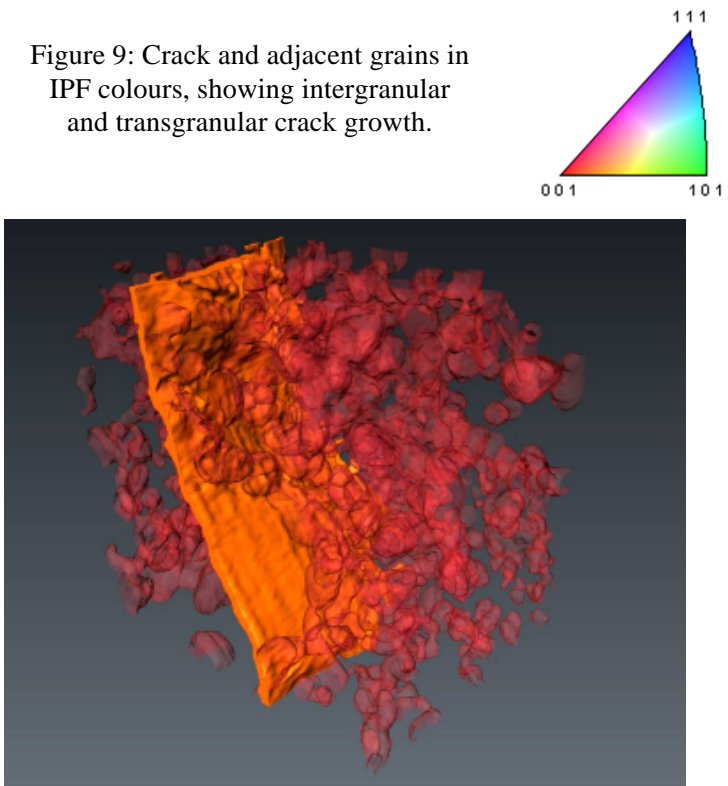

Figure 10: Crack and primary $\gamma^{\prime}$ showing the interaction of crack and microstructure, grains can be inferred.

From the EDX data collected the primary $\gamma^{\prime}$ were reconstructed by consideration of the chromium maps, which have shown the best results for identifying $\gamma^{\prime}$ in previous work [16] as the primary $\gamma^{\prime}$ is free of Cr. A 3D map has therefore been created from the results of the EDS chromium map showing the primary $\gamma^{\prime}$ in the volume scanned, giving some indication about grain size and distribution around and beyond the crack, and the crack has again been reconstructed from the EBSD IQ maps. This representation allows the microstructure to be visualized beyond the immediate grains around the crack tip by effectively making the $\gamma$ matrix "transparent". Viewing this in conjunction with the previous two figures for example, allows one to identify the large "void" that indicates the position of the large $\gamma$ grain containing a twin. The crack exhibits mostly transgranular crack growth in this large grain, which (Fig. 9) is apparently unaffected by the twin boundary. We can also see that the 3D distribution of primary $\gamma^{\prime}$ gives a quite different indication of how a crack tip will interact with the grain and precipitates compared to conventional 2D 
representations. Visualisation and representation of such data-rich images is challenging; the additional compositional (phase identification), orientation and deformation/strain mapping features of this approach together with the spatial information in $3 \mathrm{D}$ require new approaches to data presentation, e.g. animations are much more informative than static $2 \mathrm{D}$ pictures that are presented in a paper)

\section{Discussion}

Based on the results of the SEM fractography in both the shear and the stage II regions a similar crack growth mechanism is seen. 'Striation' like features have been observed in both stage II and deflected crack growth areas. The features change direction at grain boundaries, it is therefore concluded that the features are most likely to be slip traces. Moreover secondary cracks also occur in the same direction/orientation. They increase in size and number with higher $\Delta \mathrm{K}$ and large secondary cracks can be observed at the point where mode I controlled behaviour switches to mode II controlled behaviour in the terraced region. Both the slip traces and secondary cracks indicate a competition between Mode I and II controlled crack growth modes. In the region near the free surface this leads to macroscopic deflection under mode II loading and then back to mode I, while in the stage II (teardrop) region, there is no macroscopic deflection. Therefore the plane stress region seems to have an effect in triggering this phenomenon. However, it should be noted that the terraces extend much further than the plane stress region.

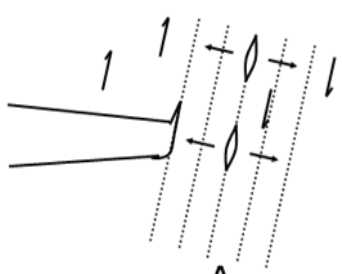

A

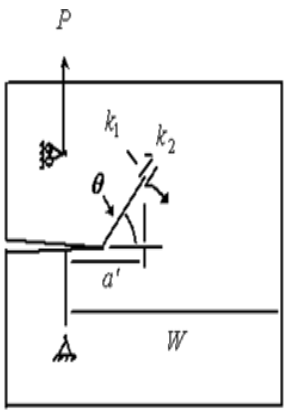

C

Figure 11: Stages of crack deflection: (A) a crack under mode I loading a small local deflection triggered by microstructural features. (B) this deflection can develop more significantly, but still be contained within the crack tip plastic zone. (C) the deflection exceeds the crack tip plastic zone, the crack could become a macroscopic mixed mode crack
Clearly TDC is a sustained macroscopic crack deflection, so it is important to consider the driving forces that have been found to control deflected crack growth in other systems. The causes of crack deflection from their nominal mode I plane (controlled by mode I far field conditions) can be described by deflection mechanics in three stages (or at three different scales), which are schematically presented in Figure 11: (a) Firstly in a crack under mode I loading a small local deflection can emerge caused by planar slip processes, obstacles to crack growth or other local deflections triggered by the microstructure. (b) Secondly this small deflection from the parent crack can develop more significantly, but still be contained within the crack tip plastic zone. (c) Finally if the deflection exceeds the crack tip plastic zone, the crack could become a macroscopic mixed mode (opening and shear mode) crack, which can be described by linear elastic fracture mechanics (LEFM) (with a local $\mathrm{k}_{1}$ and $\mathrm{k}_{2}$ controlling the crack propagation). The two first cases (Fig $11 \mathrm{~A}$ and B) occur regularly during the growth of a crack, but do not necessarily develop into a macroscopically deflected crack. Periodic changes in crack path on a microscopic scale may actually cause slower fatigue crack growth rates [8]. Clearly further analysis of the evolving crack-tip stress state for this complex phenomenon is required.

It is significant that vacuum conditions have been reported [1] to promote, while higher temperatures seem to suppress (to some extent) the deflected crack growth. Slip processes are expected to be more heterogeneous at lower temperatures and in vacuum, due to the slip reversibility in vacuum. There seems to be a link between the sustained deflected crack growth and the slip character. However, the phenomenon is suppressed at low temperature in vacuum, where slip is heterogeneous. The more detailed evaluations afforded by the 3D reconstruction of the crack tip have confirmed that the crack growth mode in sustained deflected cracks is not noticeably different from that in "Stage II" regions, with evidence of both transgranular (possibly slip-band) cracking and growth between and around primary $\gamma^{\prime}$ particles occurring. There is no evidence that any particular texture or grain orientation is responsible for the deflected crack growth.

Clearly a detailed assessment of when and how much the crack deflects is needed to understand the possible direction of cracking in components, which will affect crack growth calculations.

\section{Summary and Conclusions}

The phenomenon of sustained deflected fatigue crack growth in $720 \mathrm{Li}$ at intermediate temperatures has been studied. Fracture surfaces show a competition between opening and shear modes of crack growth, with macroscopic deflection being initiated from the free surface. The interaction of the crack and surrounding microstructure have been studied using serial FIB sectioning allowing a reconstruction based on combined 3D EBSD/EDS to be produced. This showed both intergranular and transgranular crack growth modes occurring in the deflected crack growth and that there is no obvious influence of grain orientation or texture to explain the crack deflection. The evolving crack-tip stress state as the complex 3D crack path develops must be further evaluated. 


\section{Acknowledgements}

Funding support for C. Schoettle and D.J. Child from the Engineering and Physical Sciences Research Council and RollsRoyce plc is gratefully acknowledged.

\section{References}

1 C. Schoettle, I. Sinclair, M.J. Starink, P.A.S. Reed, 2012 "Teardrop Cracking' in Nickel based Superalloys: Sustained macroscopic deflected fatigue crack growth", in press (2012) International Journal of Fatigue.

2 M. Loo-Morrey, P.A.S. Reed, “Anomalous crack shape development (tear drop cracking) in turbine disc material Udimet 720.” Materials Science and Technology, 16 (2000)133-146.

3 R.R. Brooks, W.M. Rainforth, "Fatigue damage mechanisms associated with 'tear-drop' cracking in UDIMET 720". Fatigue Fract Engng Mater Struct, 22 (1999) 821-829.

4 P.A.S. Reed, W.F. Gale, J.E. King, "Intrinsic thresholds in polycrystalline Udimet 720". Materials Science and Technology, 9 (1993) 281-287.

5. J. Tong, "Mixed-mode crack growth from an unusual source", Fatigue Fract Engng Mater Struct, 24 (2001) 771-775.

6. B. Cotterell, "Notes on the paths and stability of cracks in alloys" Int. J. Fracture Mech. 2 (1966) 526-533.

7. L.P. Pook, "On fatigue crack paths", International Journal of Fatigue, 17 (1995) 5-13.

8. P.A.S. Reed, X.D. Wu, I. Sinclair, "Fatigue Crack Path Prediction in UDIMET 720 Nickel-Based Alloy Single Crystals". Metallurgical and Materials Transactions A, 31A (2000) 109123.

9. I. Sinclair and P.J. Gregson "The effects of mixed mode loading on intergranular failure in AA7050-T7651" $5^{\text {th }}$ International Conference on Aluminium Alloys - Their Physical and Mechanical Properties (ICAA5), Grenoble, France, July 01-05, 1996 Source: Aluminium Alloys: Their Physical And Mechanical Properties, Part 4/Supplement.

10. P.A.S Reed, "Effects of warm prestressing on A533B weld metal," PhD Thesis, University of Cambridge: Cambridge, 1990 11. M. Ganesan, Rolls Royce Private Communication. 2010.

12. D.J. Child, G.D. West and R.C. Thomson, "Assessment of surface hardening effects from shot peening on a Ni-based alloy using electron backscatter diffraction techniques", Acta Materialia, 59 (12) (2011),4825-4834

13. D.J. Child, G.D. West and R.C. Thomson, "The Use of Combined Three-Dimensional Electron Back Scatter Diffraction and Energy Dispersive X-Ray Analysis to Assess the Characteristics of the Gamma/Gamma-Prime Microstructure in Alloy $720 \mathrm{Li}^{\mathrm{TM}}$ ". Ultramicroscopy, In Press, (2012), http://dx.doi.org/10.1016/j.ultramic.2011.11.003.
14. A.C. Pickard, "The application of 3-dimensional finite element methods to fracture mechanics and fatigue life prediction”, EMAS (1986) Birmingham, UK, 180 pages ISBN 0 947817220.

15. G. West and R.C. Thomson, "Combined EBSD/EDS Tomography in a Dual-Beam FIB/FEG-SEM", Journal of Microscopy, 233 (3) (2009), 442-450. 